\title{
Music two-point-zero: music, technology and digital independence
}

\section{Paul Draper Queensland Conservatorium Griffith University}

\section{Keywords}

action research knowledge transfer music 2.0 music technology praxis intervention social networking web 2.0

\section{Introduction}

To the layperson, the idea of 'music technology' once conjured up a mental picture of audio engineering personnel operating complex equipment in impressive recording studios, working in a Fordist manufacturing chain including technical staff, producers, artists, music arrangers and record company Artists and Repertoire (A\&R) managers. In the twenty-first century however, such workflow is increasingly devolved to musicians creating with portable digital systems, home recording studios and independent networks. Despite the resistance of the world's major record labels (Knowledge@Wharton 2006), the Internet has enabled a participatory culture which is transforming value systems, undermining notions of authority, and creating rhizomatic pathways for autonomous innovation. Music-making has evolved rapidly from systematized control systems of old to where digital technologies now empower musicians and audiences to make their own judgements, if necessary, to reject divisions of labour and the assertions for what constitutes 'truth' or 'quality' by big media power agencies (Benkler 2006; Lessig 2004). In a so-called 'web 2.0' phenomena 
(O’Reilly 2005) young people continue to redefine the information society:

a new paradigm in which users are co-producer of services: of content (blog, wiki, Flickr), of taste/emotion (Amazon, de.li.cious), of goods (eBay), of contacts (MySpace), of relevance (Google pagerank), of reputation/feedback (eBay, TripAdvisor), of storage/server capacity (Peer-2-Peer), of connectivity (wifi sharing, mesh networks) or of intelligence (business web2.0).

(Reding 2006: para. 6)

Artists interact both directly and virally in what Thomas Friedman (2005) calls 'The Flat World', while attending to a new economics of attention (Lanham 2006) to launch and support independent careers. This includes composing, recording, filming, direct merchandizing, concert tour promotions and engaging with fan bases and other communities of practice via resources such as wikis, blogs, podcasting services and digital music download stores. Music technology is recast as 'music 2.0'.

\section{The research location}

This project was set in a music technology department delivering a range of undergraduate and postgraduate degree specializations within an Australian university-based conservatorium of music. From its inception in 1983, the department featured a strong sense of community, to some degree propelled by practical product outcomes and a vocational focus. Being technologically oriented, the cohort was an early adopter of what has come to be known as 'blended learning' (Bersin 2004), that is, a pedagogically crafted amalgam of ICT and faceto-face studio teaching.

Since the turn of the century, however, higher education ideology has been increasingly consumed by 'massification'. This includes a preoccupation with branding, where universities controlled websites as marketing and information delivery tools, while classroom timetables and e-learning systems aimed to systematize, scale and distribute pedagogical models which, in effect, compartmentalized students' educational opportunities, both on-line and off (Draper 2007). This has not proven to be a good fit with conservatoria traditions of collaboration, project-based learning, studio-based teaching and 'thinking through making' (Fitzgerald 2007). In the music technology department in question, concerned academic discussion and subsequent student programme evaluations revealed that increasingly:

- Knowledge transfer was poor across classes or degree year levels

- students remained separated into persistent cliques of smaller groups

- networking was viewed as unimportant

- there was a disconnect with the changing nature of career pathways.

Although the romanticized 1970s-styled, star-driven model of the record company, the artist and the multi-million dollar recording studio is no longer widespread, the classroom revealed that many students maintained outdated conceptions of just what professional musicians 
did and how they made a living. Inexperience, together with the folklore of the trade magazines and mass-media hyperbole tended to assure this (Lessig 2004). Older or time-poor faculty staff and administrators often remained decades out of touch with contemporary, perhaps puzzling new viral practices as elaborated in a recent US MacArthur Foundation report:

our schools are still focused on generating autonomous learners; to seek information from others is still classified as cheating. Yet, in our adult lives, we are depending more and more on others to provide information we cannot process ourselves. Our workplaces have become more collaborative; our political process has become more decentered ... our schools are not teaching what it means to live and work in such knowledge communities, but popular culture may be doing so.

(Jenkins et al. 2007: 129)

A 'long tail' environment (Anderson 2006) has been enabled where hierarchies are flattened and value is created less within vertical silos and more through horizontal collaboration. This allows for niche music, eclectic tastes, new audiences and a breakdown of former cultural, territorial or stylistic barriers. Disintermediation removes the middleman (Wikipedia 2007a) so that the role of producers and consumers blurs and merges across networks of so-called 'prosumers' (Toffler 1980). In his book The Wisdom of Crowds, James Surowiecki (2004) explores this further: the idea that large groups of people are smarter than an elite few, no matter how brilliant - better at solving problems, fostering innovation, coming to wise decisions, even predicting the future. Or as philosopher Pierre Lévy puts it in his concept of collective intelligence:

Rather than distribute a message to recipients who are outside the process of creation and invited to give meaning to a work of art belatedly, the artist now attempts to construct an environment, a system of communication and production, a collective event that implies its recipients, transforms interpreters into actors, enables interpretation to enter the loop with collective action.

(Lévy 1999: 123)

\section{Aims of the study: maintaining authentic ontologies}

This project aimed to incorporate such Web 2.0 characteristics into the ways in which a music technology department intervened in response to contemporary challenges for pedagogy, learning environments and graduate opportunities. It did so by approaching this from an ontological perspective to consider social networking as a tool to embed and stimulate department-wide dynamic knowledge transfer within learning processes and creative projects, as suggested in the work-integrated learning literature:

current research and development concentrates more on what we can do as soon we have ontologies - rather than having a closer look at the 
processes of creating and especially maintaining such domain-specific ontologies...users are almost constantly constructing and negotiating shared meaning in collaboration with others by augmenting and evolving a community vocabulary. The main challenge is then how to leverage this implicit and informal ontology building for explicit formal models needed for semantic approaches.

(Braun et al. 2007: 1)

Rather than begin with the application of technological solutions to learning problems applied from the 'top down', this project worked from the 'inside out', that is, from an intention to reclaim a natural participatory ecology as might be appropriate to the aforementioned music 2.0 proposition.

\section{Methodology: praxis intervention through action research}

The term 'praxis' denotes the interaction between theory and application that keeps both vivid, relevant and truthful (Wilson 1994). Given the concerns raised above regarding the changed contexts for such interaction, this paper approaches the research as a praxis intervention project (Wikipedia 2007b) through a series of action research cycles (Kemmis and McTaggart 1988) - to plan, act, observe, review - in a reflective process of progressive problem-solving, led by individuals working as part of a community of practice, in order to improve the way it addresses issues of authenticity where music education is caught amid the triple-pincer pressures of

1. The demands of conformity in systematized classroom, timetabling and e-learning systems

2. Outmoded preconceptions of professional music practice

3. An imperative for authentic literacies, ontologies and twenty-firstcentury praxis.

The research design presents a longitudinal study which examines the outcomes of interrelated projects, all of which have been the subject of both traditional and non-traditional publication outcomes over time (that is, scholarly papers, websites and multimedia products). The study has been arranged sequentially as three action cycles, each of which summarizes discrete themes, approaches and findings but, with the additional benefit of hindsight and historical perspective, maps the community's evolving practice across the period 2002-2007. Common methodological details are as follows.

\section{Demographics}

The project focused on the department's flagship offering, the Bachelor of Music Technology, a three-year degree with a fourth-year honours option. While the programme once attracted a wide range of age groups and backgrounds, since 2000 the cohort has almost exclusively comprised school leavers and younger students in the 17-21 age group. In the same period, female enrolments had increased and stabilized at approximately one quarter of all students in a population of 65 at any given time. Each 
year graduated and enrolled around twenty places, thus this study captured aspects of the activities of some 165 students over a six-year period. In terms of professional input, the project drew upon the collaboration of two music technology academics, six casual teaching staff and a range of external colleagues in education and industry, all of whom have contributed to various outputs as cited in each of the action cycles.

\section{Research instruments}

The most common data-collection instrument used throughout has been the university's course evaluation questionnaire, electronically administered to all students at the end of each semester via the online Blackboard system. This picked up common quality-related themes but might have been under-utilized by students if left only to self-administration. Therefore, in addition, staff convened end-of-semester debriefs which enlivened aspects of the survey process and facilitated workshop discussion on topics closely related to a specific concern. For example, in each action cycle it was an increasingly natural activity for students and teachers to critique initiatives such as the online discussion board, work placements, podcasting or team-based creative projects.

Such sessions were surveyed, noted, recorded or, in some, cases video-taped. Ethics were managed in an open fashion where students agreed that the data could be used for the purposes of teaching, learning and research and especially in terms of continually improving their environment. In cases where a student's intellectual property might have been used outside this framework, Creative Commons licences provided clarification and assurance regarding the integrity of the attribution for their work. Regular academic meetings were held to review datasets, the quality and intent of course assessment items, to discuss perspectives, problem-solve, and come to common understandings of what the feedback and the on-the-ground interactions might have indicated. Typically, around 75 per cent of all students actively participated in both the data collection and the subsequent critique of analyses and/or outcomes, including new resources, systems and publications.

\section{Application}

The first action cycle was primarily concerned with setting the pedagogical framework, the resources and local culture from which the following cycles emerged. This drew upon earlier research into problem-based learning (Draper 1999), discovery learning (Bruner, 1959; Shulman and Keislar 1966) and experiential learning (Kolb 1984), resulting in the creation of project-based assessment activities, team assignments, inter-year student fora and other informal networks or online resources. Data collection, analyses and publications were drawn from student surveys and workshops.

The second cycle investigated student industry placements and the development of professional skills in new contexts, often quite different from student (and staff) preconceptions. Placements were implemented with the full support, insurance and legal framework of the university and were managed by academic and industry supervision teams. The data collection and analysis here widened beyond student surveys to include the assessment activities themselves: students presented ongoing 
workshops and reporting to their peers, teaching staff and industry employers. Results were discussed broadly across the entire cohort and employers had extensive opportunity to provide input via interviews, presentations to the student body and other university networking events.

The third cycle examined the step of disseminating original work and assessment items via the Internet and public performance. This phase acknowledged the evaluation mechanisms developed earlier, but also incorporated national/international interactions, Web 2.0 metrics and virtual collaboration. Students began to deliver their own self-reviews and analyses of material, became more proactive in suggesting novel ways of approaching artistic and academic development, and the research interrogation began to focus on data from specific case studies.

In sum, the task here is now to present a coherent summary of the findings over time, to elaborate on notable aspects of the interventions, and to posit a future trajectory for the research.

\section{Action cycle 1: redefining the learning ecology (from 2002)}

When e-learning (Blackboard) was introduced in 2000, this worked as a simple delivery device for teacher-authored content but was weak in supporting a cohort-wide community of practice. Segregated by subject and year level, artistic communication and collaboration became difficult while assessment policy for creative works was systematized and criteria driven (increasingly, managed by casual staff). Yet, in 'thinking through making', music is typically social and highly interactive, with contributors sharing ideas, techniques and performances to make a whole. Therefore a number of approaches evolved to reclaim the curriculum and its pedagogy, as shown in Table 1.

\section{Synopsis 1}

Peer review and assessment was undertaken both in class settings and through cohort-wide discussion groups and teams: students presented their thinking to others, who provided feedback and questions, discussed variants and in general, learned about the meta-contexts in which their work resided. A semiotics of the discipline developed and exemplars of excellence were acknowledged and rewarded not only through course grades, but also through informal networks. Overall, students were encouraged to be responsible to their peers, aiding the need "not for more professional knowledge from external sources, but for greater self examination skills and higher levels of self awareness to appreciate the skills they already have' (Grainger 2001: 2).

Local research (Carey et al. 2006; Draper 2005) indicated that such mechanisms continued to improve and enhance the intended learning aims, overall engagement and creative outcomes for these students. However, while the context for on-campus collaboration became more refined, the concept of 'the workplace' remained elusive. Students and staff tended to cling to the 'star-driven' model, while the university sought inappropriate metrics around graduate destination surveys and corporate employer profiles - for freelance creatives, this often made little sense, thus prompting another action cycle accordingly. 


\begin{tabular}{|l|l|l|}
\hline Activity & Approach & Resources \\
\hline $\begin{array}{l}\text { Problem- } \\
\text { based } \\
\text { Learning } \\
\text { (PBL) }\end{array}$ & $\begin{array}{l}\text { In studio courses, assessment included responding } \\
\text { to a range of 'problems' such as the production of } \\
\text { concert recordings, popular music and jazz albums } \\
\text { and original music/sound for film. Projects were } \\
\text { led by the creative brief; theory and technique was } \\
\text { unpacked in supporting courses where students } \\
\text { drew upon the examples of more advanced peers } \\
\text { in cross-year, team-based projects. }\end{array}$ & $\begin{array}{l}\text { Student gallery and media } \\
\text { archives available at } \\
\text { www29.griffith.edu.au/ } \\
\text { mutech/eportfolio_archives }\end{array}$ \\
\hline $\begin{array}{l}\text { Music } \\
\text { Technology }\end{array}$ & $\begin{array}{l}\text { A face-to-face, weekly meeting to facilitate interac- } \\
\text { tions between students and staff, where problem } \\
\text { solving outcomes were reviewed. Forum also served } \\
\text { to feature alumni workshops and student work } \\
\text { placement reports. }\end{array}$ & $\begin{array}{l}\text { MTF: cohort-wide staff and } \\
\text { student workshops using } \\
\text { smart lecture theatre, } \\
\text { including wireless access, } \\
\text { OHP, 5.1 sound. }\end{array}$ \\
\hline $\begin{array}{l}\text { Resource } \\
\text { Booking } \\
\text { System (RBS) }\end{array}$ & $\begin{array}{l}\text { Students self-managed their access to institutional } \\
\text { resources, including recording studios, mobile } \\
\text { equipment and sound-reinforcement systems. They } \\
\text { worked from time-based quotas and learned to } \\
\text { interact with technical staff and the institution } \\
\text { just as professionals would be expected to. }\end{array}$ & $\begin{array}{l}\text { RBS: available at } \\
\text { www29.griffith.edu.au/rbs } \\
\text { (requires LDAP authentica- } \\
\text { tion). Based on open source } \\
\text { MRBS mrbs.sourceforge.net. }\end{array}$ \\
\hline $\begin{array}{l}\text { MuTech } \\
\text { Board (MDB) }\end{array}$ & $\begin{array}{l}\text { A moderated, web-based discussion board drove key } \\
\text { themes and aided in promoting exemplars of student } \\
\text { achievements, cross-faculty project calls and job } \\
\text { opportunities. This resource retained the member- } \\
\text { ship and input of alumni, other university schools } \\
\text { and industry partners. }\end{array}$ & $\begin{array}{l}\text { MDB: a moderated forum for } \\
\text { students, staff and alumni. } \\
\text { Available at: www29. } \\
\text { griffith.edu.au/discussions. } \\
\text { Based on open source phpbb2 } \\
\text { www.phpbb.com. }\end{array}$ \\
\hline
\end{tabular}

Table 1: Knowledge transfer across the music technology learning ecology.

\section{Action cycle 2: reconceptualizing work-integrated learning (from 2005)}

Work-integrated Learning (WIL) became increasingly popular in the Australian higher education sector (Flinders University 2006), aiming to provide a structured method of combining education with practical work experience by providing academic credit for career work under the supervision of teachers and industry partners. However, WIL suffered from 'boomer' preconceptions, where notions of the shop floor, apprenticeship and professional progression were embedded into the thinking. In new creative industries and online environments, these ideas increasingly lacked meaning when there was no longer a physical factory to work in, nor a management command structure to negotiate with.

As evidenced by Forum and Discussion Board exchanges, the range of work opportunities for audio specialists had increased exponentially to 
include radio, film, ICT, education, forensics, arts management and other creative clusters (Hartley 2005). It was also revealed that graduates did not necessarily identify with these workplaces and often experienced integration difficulties in their first few years out. Despite excellent learning ecology interactions with staff, alumni and industry, it was apparent that students required in situ work experiences before they graduated; while still universityresident, students with work experience might then also be able to feed back their experiences to peers. Led by a small start-up grant, music technology's first WIL offering was subsequently devised - the Music Technology Industry Affiliates Program (MTIAP) was launched in 2005 as a singlesemester, 13-week placement for final year undergraduates, who took on a range of jobs with schools, television broadcasters, live sound agencies and independent music production houses.

\section{Synopsis 2}

A subsequent study (Draper and Hitchcock 2006) highlighted the following key findings:

- Students provided positive feedback about their growth in self-confidence, and workplace appreciation for what they had to offer as highly trained, creative people.

- There was widespread realization that being a professional was less about applying set skills in known situations, but more about the application of abilities in unknown situations.

- Students said they enjoyed 'real world' pressures which focused their abilities to put knowledge into action (puzzling to academics, who found such apparently desirable pressure difficult to replicate in the classroom students continued to cram and leave projects to the last minute).

- Many workplace supervisors initially underestimated the specialist skill level and creativity of students, and later indicated positive changes, upgrades in practice and genuine knowledge transfer that often occurred in the workplace as a result of student input.

On the negative side, industry was repeatedly highly critical about the lack of inclusion of context-related abilities within arts programmes in general. Employers and alumni commented that universities separated business development classes from craft studies - students could technically 'do the job' (craft) but had no idea of meaning in relation to a 'big picture' (context), that is, the curriculum represented neither the 'real world' of law and business, nor the common-sense world of the creative artist (Draper et al. 2006). This included matters relating to workflow, collaborative roles, deliverables and intellectual property (IP) - for example, under music copyright law, unless otherwise agreed, the ownership of sound recordings resides with all of the creators: sound producers, composers and performers. Some industry partners called for better, small-business-like subcontracting arrangements, including virtual workflow, team collaboration and timeframe flexibility. It was subsequently proposed that music technology review its resources to explore the embedding of professional interaction in craft production, using the Internet as a common vehicle to span developments thus far. 


\section{Action cycle 3: open publishing project (from 2006)}

Given the preceding discussion, a number of considerations therefore came into play:

1. Music technology infrastructure included two Apple computer servers (Xserves) and some 40 workstations across recording studios, laboratories and mobile units. These facilities were interconnected with the conservatorium's concert halls, which regularly delivered student and staff concerts to paying audiences. If the conservatorium could effectively run as a professional arts organization and place student learning in the public domain, perhaps the technology might be used more deliberately in this local creative industry to develop and promote new WIL modes?

2. In an effort to provide a greater range of literacy opportunities, students were offered the option to develop podcasts as reflective reviews and analyses of the creative works in question.

3. IMERSD (Intermedia, Music Education and Research Design) (2004) is a 5.1 surround sound and multimedia production studio which was quarantined outside of the traditional learning and teaching framework and commissioned to target key development projects, undertake research and provide a trickle-down to the mainstream. It was proposed that the unit could also provide work placement and/or research assistant roles for music technology and research higher degree students, where they assisted staff and visiting artists in this professional setting.

4. Because IP and the idea of 'contracts' was one of the most oft-cited areas of confusion, this was also a target for development. Just as WIL employers had suggested (Draper and Hitchcock 2006), to date, the curriculum had responded only through music industry lecture-based electives. Given the recent establishment of the Creative Commons Australia project (CCau 2006), this was seen as one way to develop practical insights into ownership, attribution and related negotiations.

A pilot Creative Commons project was held across an intensive project week in May 2006, where a handbook of materials was devised (Draper 2006) and published to discuss, teach and embed basic IP understanding within practical final-year undergraduate music-making projects: in this case, through original musical compositions, live concert performances, studio recordings, and subsequent streaming and podcasting. Workshops were prepared and delivered by music technology and jazz department staff, with the assistance of a leading Australian digital IP attorney. The process used a CCau Attribution-NonCommercial-NoDerivatives License where IP was positioned as a licensing agreement - from the students to the university. The two Apple Xserves were redeveloped for dedicated functions as follows below. From the outset, Google Analytics (2006) was used to gather web metrics for later evaluation.

One Xserve operated as a dedicated web server to host the Radio IMERSD (2006) content management system, modelled on an e-journal approach by inviting original digital contributions from academic staff, students and visitors. Submissions were peer reviewed and used CCau licenses, together with media format guidelines. Publications were disseminated on 
the Internet as on-demand audio, podcasts and vidcasts using iTunes 'oneclick subscribe'.

A second Xserve provided the media-streaming 'back end' and also hosted copyright-protected materials for distribution on the university intranet via a NetRadio (2006) feature. Until 2006, commercial recordings could not be legally duplicated or distributed for the purposes of teaching and research. The recent signing of the AVCC-Music Societies agreement by Griffith University (2006) allowed this, albeit given substantial licensing fees and IP-restricted streaming only. To highlight the copyright complexities enforced herein: Radio IMERSD provided conservatorium cohorts with intranet playlists of original sound productions, of original staff and student concert performances, and of only those approved compositions controlled by Australian collection societies APRA/AMCOS (2006).

\section{Synopsis 3}

At the time of writing, the content is significant: hundreds of performances are now disseminated on Radio IMERSD for review and reflection by the conservatorium's staff and student body. Open Internet publications include categories for original music in concert performances, public lectures by visiting scholars, recording studio productions, student portfolios and self-reflective reviews located under e-learning. After a six-month trial, at December 2006 Radio IMERSD was ranked 14 in education podcasting on the Australian iTunes Store (2006).

Initial research (Draper 2007) indicated promising engagement and an overall strengthening of an established community of practice. CCau licensing unpacked new meaning for students and staff in recognizing their rights and those of others, in understanding more about the often multiple-owner nature of the music business and in preparing such discussion as an integral part of the creative process. As public broadcasts, student creations often invoked greater professionalism, innovation and personal independence. For example, a final-year undergraduate undertook parallel classes that he argued as being usefully connected: one required the development of a written research paper, the other, the production of original sound production portfolio. The connecting theme he proposed was 'What is a Music Technologist?', expressing some frustration in how his industry and art form were poorly understood. Along with the paper, he realized an engaging sound-production concept through a nonspecialist, enhanced podcast series (Wyeth, 2006).

Further enquiry (Draper and Hitchcock, forthcoming) extracted additional insights into students' attitudes to their use of the web in the curriculum. Common themes are summarized in Table 2 .

It was revealed that more than three-quarters of surveyed students maintained a MySpace account and/or external website for the purposes of self-promotion and creative opportunities. However, there was apparently poor connection (resistance even) between the personal context for their art or 'fun' and the university setting for learning, assessment and degree-progression rules; while some of this activity notionally sought small-business-styled outcomes, this was unsupported by relevant technical or practical application, where limited success came by chance or personal connections rather than by any informed approach per se. 


\begin{tabular}{|c|c|c|}
\hline Question & Positives & Negatives \\
\hline \multirow{4}{*}{$\begin{array}{l}\text { Has use of the web } \\
\text { changed as a result } \\
\text { of this project? }\end{array}$} & Awareness of web as workspace. & $\begin{array}{l}\text { Didn't effect any change as they } \\
\text { already knew what to do. }\end{array}$ \\
\hline & $\begin{array}{l}\text { Observing others' work had changed } \\
\text { their own work. }\end{array}$ & $\begin{array}{l}\text { Did not know that Radio IMERSD } \\
\text { existed. }\end{array}$ \\
\hline & $\begin{array}{l}\text { Exemplars and context stimulated } \\
\text { personal research into the area. }\end{array}$ & \multirow[t]{2}{*}{ The web is for fun, not work. } \\
\hline & $\begin{array}{l}\text { Realization that it could help employ- } \\
\text { ment prospects. }\end{array}$ & \\
\hline \multirow{4}{*}{$\begin{array}{l}\text { Impact on profes- } \\
\text { sional standards and } \\
\text { personal development }\end{array}$} & $\begin{array}{l}\text { A greater sense of involvement and } \\
\text { ownership of learning. }\end{array}$ & \multirow[t]{2}{*}{$\begin{array}{l}\text { Did not know that Radio IMERSD } \\
\text { existed. }\end{array}$} \\
\hline & $\begin{array}{l}\text { Understanding of context and applica- } \\
\text { tion of technology. }\end{array}$ & \\
\hline & $\begin{array}{l}\text { Helped understand future expectations } \\
\text { and directions. }\end{array}$ & \multirow[t]{2}{*}{ No 'self-change', wait for 'teaching'. } \\
\hline & Raised the standard of work. & \\
\hline \multirow{4}{*}{$\begin{array}{l}\text { Impact on learning } \\
\text { and the learning } \\
\text { community }\end{array}$} & $\begin{array}{l}\text { A greater sense of involvement in } \\
\text { teamwork to produce content. }\end{array}$ & Irrelevant activity for students. \\
\hline & Sharing and promoting new ideas. & Didn't know about the project. \\
\hline & Produced a sense of competition. & No one told me. \\
\hline & $\begin{array}{l}\text { Pride and ownership for those whose } \\
\text { had their work posted. }\end{array}$ & No 'self-change', wait for 'teaching'. \\
\hline \multirow{4}{*}{$\begin{array}{l}\text { Has the prospect of } \\
\text { external publication } \\
\text { altered approaches } \\
\text { to assessment? }\end{array}$} & Greater aesthetic awareness. & \multirow[t]{2}{*}{ My work is always high quality. } \\
\hline & $\begin{array}{l}\text { More attention to emulating quality of } \\
\text { others' work. }\end{array}$ & \\
\hline & More effort was applied. & The web is for fun, not work. \\
\hline & Better detail in presentation. & Didn't know about the project. \\
\hline
\end{tabular}

Table 2: Survey results of 45 music technology undergraduates $(M=34, F=11)$.

\section{Summary comments: the hidden curriculum}

The most significant impacts have been in the areas of the local learning community and in terms of assessment, logically so, because much foundation work has been undertaken here in past years (see Action cycle 1), and where students actively passed such ecological understanding on to each new year of student intake. The areas lacking in uptake were those 
where the art was placed in the external domain, or in as yet not-considered 'working' contexts. To reflect on Radio IMERSD as a one-year-old project, the results are encouraging, but clearly more work has to be done in terms of embedding this further in teaching approaches, alumni/industry participation, and in the development of specialized opportunities for students to engage in this new territory in meaningful ways.

The most striking aspect of the project was in relation to the enculturation and ownership that took place as a result of use of the MBD by students (see Table 1, MuTech Discussion Board). The MDB effectively functioned as a powerful 'hidden curriculum' (Jenkins et al. 2007) which not only maintained an evolving and transparent historical record of local knowledge, but provided a bridge across university time and space which reclaimed and promoted the development of important personal and professional competencies. The music technology department's most recent 2007 exit survey indicated that the majority of students believed that the MDB provided:

- promotion of collaboration and critical thought

- a tool for learning, research and discussion to support face-to-face projects and practices

- enhanced opportunities for self-reflection (and were often surprised at these outcomes)

- a new kind of academic support - freedom vs. instruction

- raised confidence, due to community interactions

- immediate access to the community, to meet a lot of people in a short amount of time

- an essential off-campus access point to the university where peer networking and engagement is important - quite distinct from online materials such as texts or lectures.

The MBD has integrated metrics tools which have demonstrated, over six years of operation, that the most highly ranked and engaged discussion themes included:

- social networking and bonding

- technical hints, tips and information

- business, marketing and publication

- creativity and perspectives of the creative process

- qualitative judgements where there might be no 'right' answer.

Internet metrics provided unexpected outcomes: over a six-month trial in the second half of 2006, the IMERSD website took part in a web-tracking project using Google Analytics tools (2006). September 2006 attracted some 850,000 visitors, while individual institutions in remote countries continued to return in significant numbers to access selected materials (Braue 2006). In one case, an IP in Dublin downloaded a single work on some 700 occasions and overall, podcasting reach has substantially expanded via aggregation on external sites (Podcast Directory 2007). All of this continues to drive student engagement and commentary but, more centrally, has been of interest to other, non-music, academics and has 
generated plans for university e-research development. In music technology, this promises engaging research-led teaching in the future.

\section{Concluding remarks}

Somewhat cautiously, Gabriel Jacobs (2005) produced some wellargued research in a recent education technology journal, questioning the benefits of hypermedia and so-called 'discovery learning', in which she says, 'the aim of educating students such that they can transfer learning to unfamiliar problems and situations is not... achieved by giving them their reins before they have learned to walk safely. Hypermedia technology, for all its great potential... is a dangerous weapon in the hands of the inexpert' (Jacobs 2005: 7). University of Georgia's Tom Reeves adds:

Although there are many advocates of discovery-based environments for the learning of social studies, science, and even mathematics in schools, most of these people would probably prefer their brain surgeons to be trained via direct instruction.

(Reeves, 1995: 8)

It would be fair to say that conservatoria have indeed maintained a strong tradition of direct instruction. Craft and technique reign supreme, but what is under scrutiny here is the changed context and nature of contemporary music-making identified herein as 'music 2.0' - which surely is neither rocket science nor brain surgery. We also must be cognisant of the fact that conservatorium training is heavily impacted upon by an increasingly corporate-like 'one size fits all' higher education environment.

Clearly, music schools should rightly argue loudly and strongly to be places of higher learning - if you will, art for art's sake, not necessarily connected to commercial outcomes, but rather, to promote higher-order thinking, creativity and excellence in craft. Still, neither can educators afford to ignore the fact that many students desire vocational success - in this case to be able to work rewardingly as a professional musician/technologist. Australian university targets and funding flows are increasingly tied to metrics-based schema, graduate destination surveys and measurements of value-adding to society as defined by the federal government. If global 2.0 trends are significant indicators for consideration, then key drivers of authentic knowledge transfer will need to be further developed and enabled by creative arts faculties, in turn to be appropriated and adopted by the students themselves - not imposed from the top down, but evolved, maintained and valued from the inside out.

\section{Works cited}

Anderson, C. (2006), The Long Tail: Why the Future of Business is Selling Less of More, New York: Hyperion.

APRA/AMCOS (2007), Australasian Performing Right Association and the Australasian Mechanical Copyright Owners' Society, www.amcos.com.au/general/ aboutUs.asp. Accessed 16 August 2007.

Benkler, Y. (2006), The Wealth of Networks: How Social Production Transforms Markets and Freedom, New Haven and London: Yale University Press. 
Bersin, J. (2004), The Blended Learning Handbook: Best Practices, Proven Methodologies, and Lessons Learned, San Francisco, CA: Pfeiffer Wiley.

Braue, D. (2006), 'IMERSD podcasts @ Griffith University'. Apple University Consortium Wheels for the Mind, 16: 2, pp. 8-9, http://auc.uow.edu.au/Wheels+for+the+ Mind. Accessed 2 November 2007.

Braun, S., Schmidt, A. and Walter, A. (2007), 'Ontology Maturing: A Collaborative Web 2.0 Approach to Ontology Engineering', in Proceedings of the Workshop on Collaborative Construction of Structured Knowledge (CKC) at the 16th International World Wide Web Conference, 8-12 May 2007, Banff, Canada.

Bruner, J. S. (1959), 'Learning and Thinking', Harvard Education, 29, pp. 184-92.

Carey, G., Draper, P., Lebler, D. and McWilliam, E. (2006), 'Learning and Unlearning: New Challenges for Teaching in Conservatoires', Australian Journal of Music Education, 1, pp. 25-31.

CCau (Creative Commons Australia) (2006), 'The Australian Derivative Project of the Creative Commons Project in the USA', http://creativecommons.org.au. Accessed 20 August 2007.

Draper, P. (1999), 'New Learning: The Challenge of Flexible Delivery in Higher Education', doctoral thesis, Australasian Digital Theses Program, NBD: 22751314, www29.griffith.edu.au/imersd/draper/edd. Accessed 20 October 2007.

(2005), 'Encounters: Subdisciplinary Dynamics in Australian Music-making and Recording', paper presented at the Art of Record Production Conference, London, Royal Holloway College, 17-18 September.

— (2006), Concert Stream: Project Week 2-5 May 2006, project handbook and teaching materials, www29.griffith.edu.au/imersd/stream/concerts/projectweek 040506. Accessed 20 October 2007.

(2007), 'Students Doing the Driving: How Undergraduates Use ICT to Enhance Reflective Practice, Peer Review and Collaborative Learning', in refereed proceedings of Music in Australian Tertiary Institutions - Issues for the 21st Century. Proceedings of the NACTMUS National Conference, Brisbane 29 June-1 July 2007. Draper, P., Hall, M. and Wilson, J. (2006), 'Universities, Creativity and the Real World?', in refereed proceedings of Speculation and Innovation Conference, Brisbane, 30 March-1 April 2005.

Draper, P. and Hitchcock, M. (2006), 'Work-integrated Learning in Music Technology: Lessons Learned in the Creative Industries', Asia-Pacific Journal of Cooperative Education, 7: 2, pp. 24-31.

(forthcoming), 'The Hidden Music Curriculum: Utilising Blended Learning to Enable a Participatory Culture', paper to be presented at The 28th International Society for Music Education (ISME) World Conference, 20-25 July 2008, Bologna, Italy.

Fitzgerald, R. (2007), 'National Art School Fighting a War of Independence', The Australian, Opinion, 27 November, p. 47.

Flinders University (2006), Teaching Strategies: Benefits of Work-integrated Learning, Teaching and Learning @ Flinders, www.flinders.edu.au/teach/t4l/practicum/ benefits.php. Accessed 16 July 2007.

Friedman, T. (2005), The World is Flat: A Brief History of the 21st Century, New York: Farrar, Straus \& Giroux.

Google Analytics (2006), An open resource dedicated to measuring and tracking web traffic through a nominated site, www.google.com/analytics. Accessed 15 September 2007. 
Grainger, S. (2001), Accessing Professional Artistry: The Importance of Cooperative Education and the Limitations of Classical Research', Asia-Pacific Journal of Cooperative Education, 2: 1, pp. 1-5.

Griffith University (2006), Music Copyright, policy on the use of music and the terms of the tertiary music license agreement, www.griffith.edu.au/ins/copyright/ content_music.html. Accessed 15 May 2007.

Hartley, J. (ed.) (2005), Creative Industries, Oxford, UK: Blackwell Publishing.

IMERSD (Intermedia, Music Education and Research Design) (2004), www.griffith. edu.au/imersd. Launched by the Queensland State Government, in 2004, IMERSD is a practice-based research unit of the Queensland Conservatorium Research Centre. Accessed 5 November 2007.

iTunes Store Australia (2006), Podcasts/education, December 2006, www.apple. com/au/itunes/store. Accessed 22 December 2006.

Jacobs, G. (2005), 'Hypermedia and Discovery Based Learning: What Value?', Australasian Journal of Educational Technology, 21: 3, pp. 355-66.

Jenkins, H., Purushotma, R., Clinton, K., Weigel, M. and Robison, A. J. (2007), Confronting the Challenges of Participatory Culture: Media Education for the 21st Century, an occasional paper on digital media and learning. Chicago, IL: The MacArthur Foundation.

Kemmis, S., and McTaggart, R. M. (eds). (1988), The Action Research Planner (3rd edn), Geelong: Deakin University Press.

Knowledge@Wharton (2006), From Confrontation to Experimentation: The Music Industry is Playing a New Tune, http://wharton.universia.net/index.cfm?fa= viewArticle\&id=210. Accessed 1 October 2007.

Kolb, D. A. (1984), Experiential Learning: Experience as the Source of Learning and Development, Englewood Cliffs, NJ: Prentice-Hall.

Lanham, R. A. (2006), The Economics of Attention: Style and Substance in the Age of Information, Chicago: The University of Chicago Press.

Lessig, L. (2004), Free Culture: How Big Media Uses Technology and the Law to Lock Down Culture and Control Creativity, New York: Penguin Press.

Lévy, P. (1999), Collective Intelligence: Mankind's Emerging World in Cyberspace, (R. Bononno, Trans.), Cambridge, MA: Perseus Books.

NetRadio (2006), a component of Radio IMERSD which broadcasts a range of musical material on the Griffith University intranet, www29.griffith.edu.au/ radioimersd/content/view/31/35. Accessed 3 June 2007.

O'Reilly, T. (2005), What is Web 2.0: Design Patterns and Business Models for the next Generation of Software, Sebastopol, CA: O'Reilly Media, www.oreilly.com/pub/a/ oreilly/tim/news/2005/09/30/what-is-web-20.html. Accessed 16 August 2007.

Podcast directory.com (2007), a podcast aggregation site, www.podcastdirectory.com/ podcasts/17806. Accessed 5 November 2007.

Radio IMERSD (2006), Podcasts and on-demand Internet audio streams of conservatorium concert recordings. Under copyright law, these broadcasts are accessible only to local university students and staff, www29.griffith.edu.au/radioimersd. Accessed 5 November 2007.

Reding, V. (2006), 'The Disruptive Force of Web 2.0: How the New Generation will Define the Future', member of the European Commission responsible for Information Society and Media, Speech presented at the Youth Forum, ITU Telecom World Hong Kong, China, 3 December.

Reeves, T. (2005). 'Evaluating What Really Matters in Computer-based Education'. Georgia: University of Georgia. http://www.medicine.mcgill.ca/ibroedu/ 
review/Reeves Evaluating What Really Matters in Computer-Based Education. htm. Accessed 4 September 2007.

Shulman, L., and Keislar, E. (1966), Learning by Discovery: A Critical Appraisal. Chicago: Rand-McNally.

Surowiecki, J. (2004), The Wisdom of Crowds: Why the Many are Smarter than the Few and How Collective Wisdom Shapes Business, Economies, Societies and Nations, New York: Doubleday.

Toffler, A. (1980), The Third Wave, New York: Random House.

Wikipedia (2007a), 'Disintermediation', http://en.wikipedia.org/wiki/ Disintermediation. Accessed 3 October 2007.

— (2007b), 'Praxis intervention', en.wikipedia.org/wiki/Praxis_intervention. Accessed 3 October 2007.

Wilson, B. G. (1994), The Postmodern Paradigm, Denver, CO: University of Colorado.

Wyeth, D. (2006), What is a Music Technologist? Internet podcast series, available for RSS subscription, feed://www29.griffith.edu.au/rss/imersd02.xml. Accessed 5 November 2007.

\section{Suggested citation}

Draper, P. (2008), 'Music two-point-zero: music, technology and digital independence', Journal of Music, Technology and Education 1: 2+3, pp. 137-152, doi: $10.1386 /$ jmte.1.2 and 3.137/1

\section{Contributor details}

Paul Draper is a professor of digital arts in the Queensland Conservatorium Research Centre and the Centre for Public Culture and Ideas at Griffith University. He is a musician and head of music technology at the Queensland Conservatorium where he has written and convened degree programs in sound production, multimedia and popular music. Paul is the Director of IMERSD, the Australian university sector's premier 5.1 surround-sound recording and post-production studios, engaging in industry projects, work-integrated learning, research training and the creation of public value through the open access podcasting site, Radio IMERSD. Paul publishes as an active record producer and writes on higher education and the arts.

Contact: Queensland Conservatorium Griffith University, PO Box 3428 South Brisbane 4101, Australia.

E-mail: p.draper@griffith.edu.au 